JFFI. 2018; 5(2) 284-288

www.jurnal.farmasi.umi.ac.id/index.php/fitofarmakaindonesia

\title{
ANALISIS AKTIVITAS PERLINDUNGAN SINAR UV SARI BUAH SIRSAK (Annona muricata L.) BERDASARKAN NILAI SUN PROTECTION FACTOR (SPF) SECARA SPEKTROFOTOMETRI UV-VIS
}

\author{
Rahmawati", A. Muflihunna, Meigita Amalia \\ Fakultas Farmasi, Universitas Muslim Indonesia \\ rahmawati.rahmawati@umi.ac.id
}

\begin{abstract}
Sunlight contains $U V$ rays that adversely affect the skin. These adverse effects can be minimized by the use of UV protective materials, both natural and synthetic. Soursop fruit (Annona muricata L.) has a high content of polyphenol compounds, some vitamins such as vitamin C, B1 and B2. This study aims to determine the activity of $U V$ light protection on soursop juice (Annona muricata L.) by using Sun Protection Factor (SPF) calculation. The measurement of SPF values using the UV-Vis spectrophotometric method in the wavelength range from 290-320 nm. The results showed that soursop juice (Annona muricata L.) had UV light protection activity at 1\% concentration of $5,188,3 \%$ concentration of 12.242 and $5 \%$ concentration of 17,247 . The category of SPF values in a row that is medium, maximum and ultra.
\end{abstract}

Keywords: soursop fruit, SPF, spectrophotometry

\section{PENDAHULUAN}

Sinar matahari sebagai sumber cahaya alami memiliki peran yang sangat penting bagi kehidupan semua makhluk hidup. Selain memberi manfaat, sinar matahari juga dapat memberikan efek yang merugikan pada kulit. Indonesia merupakan negara yang beriklim tropis, yang memperoleh sinar matahari lebih banyak yang dapat menyebabkan kerusakan kulit akibat dari pancaran sinar ultraviolet. Pemaparan sinar ultraviolet dari matahari secara kronik akan mengakibatkan perubahan struktur, komposisi kulit dan stres oksidatif pada kulit. Efek yang ditimbulkan seperti eritema, pigmentasi dan fotosensitivitas, maupun efek jangka panjang berupa penuaan dini. Sediaan tabir surya dianjurkan penggunaannya untuk mencegah atau meminimalkan efek sinar UV yang berbahaya terhadap kulit. Pengaruh buruk dari sinar UV terhadap kulit biasanya dapat diminimalkan dengan penggunaan bahanbahan yang bersifat UV protektif (Putra et al., 2012).

Penggunaan tabir surya alami dapat diperoleh dari bahan alam, antara lain rimpang, buah, biji, bunga, batang, daun, akar, dan getah. Di mana pada bagian tumbuhan tersebut mengandung senyawa fenolik yang berfungsi melindungi jaringan tanaman terhadap kerusakan akibat radiasi sinar matahari. Selain senyawa fenolik, flavanoid juga diduga dapat menangkal radikal induksi ultraviolet (UV), dan memberikan efek perlindungan terhadap radiasi UV dengan menyerap sinar UV (Pradika, 2016).
Salah satu bahan alami yang digunakan pada penelitian ini adalah buah sirsak. Buah sirsak memiliki kandungan senyawa polifenol yang tinggi, juga banyak mengandung karbohidrat, terutama fruktosa dan kandungan vitamin seperti vitamin C, vitamin B1 dan B2 (Prasetyorini et al., 2014).

Buah sirsak mengandung antioksidan antara lain adalah vitamin C (Rahayu et al., 2012). Penggunaan antioksidan pada sediaan tabir surya dapat meningkatkan aktivitas fotoprotektif. Penggunaan zat-zat yang bersifat antioksidan dapat mencegah berbagai penyakit yang ditimbulkan oleh radiasi sinar UV, beberapa golongan senyawa aktif antioksidan seperti flavonoid, tanin, antraquinon, sinamat dan lain-lain telah dilaporkan memiliki kemampuan sebagai perlindungan terhadap sinar UV (Putra et al., 2012).

Berdasarkan uraian di atas, maka dilakukan pengujian tentang aktivitas perlindungan sinar UV sari buah sirsak (Annona muricata L.) berdasarkan nilai Sun Protection Factor (SPF) secara Spektrofotometri UV-Vis.

\section{METODE PENELITIAN \\ A. Bahan}

Sampel yang digunakan yaitu buah sirsak (Annona muricata L.) yang diambil di Kec. Masamba Kab. Luwu Utara Sulawesi Selatan. Bahan yang digunakan adalah akuades. 


\section{B. Alat}

Alat yang digunakan yaitu alat-alat kaca (Pyrex), juicer, spektrofotometer UV-Visible (Thermo), sonikator (Krisbow), timbangan analitik (O’haus).

\section{Prosedur Kerja}

1. Pembuatan Sari Buah Sirsak (Annona Muricata L.)

Sampel buah sirsak dicuci bersih dan dipisahkan kulit dan bijinya kemudian daging buahnya dimasukan dalam alat juicer, sehingga diperoleh sarinya (Malsawmtuangi et al. 2013).

2. Penyiapan Larutan Sari Buah Sirsak (Annona Muricata L.)

Larutan sari buah sirsak dengan konsentrasi $1 \% \mathrm{~b} / \mathrm{v}, 3 \% \mathrm{~b} / \mathrm{v}, 5 \% \mathrm{~b} / \mathrm{v}$, dibuat dengan cara ditimbang masing-masing 0,1 gram, 0,3 gram dan 0,5 gram. Kemudain dimasukkan dalam gelas kimia lalu dilarutkan dengan aquadest selanjutnya, diultrasonikasi selama 6 menit. Masing-masing larutan kemudian dimasukkan ke dalam labu ukur 10 $\mathrm{mL}$ dan dicukupkan volumenya dengan aquadest hingga $10 \mathrm{~mL}$, dihomogenkan kemudian disaring menggunakan kertas saring (Mbanga et al. 2014).

\section{Pengukuran Absorban}

Masing-masing larutan tersebut diukur absorbannya pada panjang gelombang 290-320 nm menggunakan kuvet quarsa $1 \mathrm{~cm}$ pada interval panjang gelombang $5 \mathrm{~nm}$ menggunakan spektrofotometer UV-Vis. Dalam pengukuran digunakan aquadest sebagai blanko. Nilai SPF dihitung dengan menggunakan persamaan Mansur (Malsawmtluangi et al. 2013, h. 151).

\section{HASIL DAN PEMBAHASAN}

\section{A. Hasil Penelitian}

Tabel 1. Nilai SPF sampel sari buah sirsak (Annona muricata L.) pada beberapa variasi konsentrasi

\begin{tabular}{cccc}
\hline Sampel & $\begin{array}{c}\text { Konsentrasi } \\
\text { Sampel Buah } \\
\text { Sirsak }\end{array}$ & $\begin{array}{c}\text { Nilai SPF Sampel Buah } \\
\text { Sirsak }\end{array}$ & $\begin{array}{c}\text { Kategori } \\
\text { SPF }\end{array}$ \\
\hline $\begin{array}{c}\text { Sampel Sari } \\
\text { Buah Sirsak } \\
\text { (Annona }\end{array}$ & $1 \%$ & 5,188 & Sedang \\
muricata L. $)$ & $3 \%$ & 12,242 & Maksimal \\
\hline
\end{tabular}

Keterangan:

Klasifikasi Kekuatan SPF (Nauclea, 2015)

a. SPF minimal $(2-4)$

b. SPF sedang $(4-6)$

c. SPF ekstra $(6-8)$

d. SFP maksimal (8-15)

e. SPF ultra $\geq 15$

Tabel 2. Nilai absorbansi (Abs) dari sampel sari buah sirsak (Annona muricata L.) dengan metode Spektrofotometri UV-Vis, setiap interval $5 \mathrm{~nm}$ pada panjang gelombang 290-320 nm

\begin{tabular}{cccc}
\hline $\begin{array}{c}\text { Panjang } \\
\text { Gelombang } \\
(\mathbf{n m})\end{array}$ & \multicolumn{3}{c}{ Konsentrasi sari buah sirsak } \\
\cline { 2 - 4 } 290 & $1 \%$ & $3 \%$ & $5 \%$ \\
295 & 0,641 & 1,494 & 2,117 \\
300 & 0,582 & 1,358 & 1,911 \\
305 & 0,542 & 1,270 & 1,787 \\
310 & 0,514 & 1,213 & 1,710 \\
315 & 0,489 & 1,163 & 1,639 \\
320 & 0,462 & 1,107 & 1,560 \\
\hline
\end{tabular}


Tabel 3. Hasil perhitungan SPF pada sampel sari buah sirsak (Annona muricata L.) konsentrasi (1\%)

\begin{tabular}{cccc}
\hline \multicolumn{3}{c}{ Sampel Sari Buah Sirsak 1\% } \\
\hline Panjang Gelombang & Absorbansi & EE $\boldsymbol{x} \mathbf{~}$ & Abs $\boldsymbol{x}(\mathbf{E E} \boldsymbol{x} \mathbf{I})$ \\
290 & 0,641 & 0,0150 & 0,0096 \\
295 & 0,582 & 0,0817 & 0,0475 \\
300 & 0,542 & 0,2874 & 0,1557 \\
305 & 0,514 & 0,3278 & 0,1684 \\
310 & 0,489 & 0,1864 & 0,0911 \\
315 & 0,462 & 0,0839 & 0,0387 \\
320 & 0,436 & 0,0180 & 0,0078 \\
& Total & & 0,5188 \\
\hline
\end{tabular}

\begin{tabular}{ll}
\hline Keterangan: & \\
$\mathrm{CF}$ & $=$ Faktor koreksi $(10)$ \\
$\mathrm{EE}$ & $=$ Spektrum efek eritema \\
$\mathrm{I}$ & $=$ Spektrum intensitas matahari \\
Abs & $=$ Absorbansi sampel \\
\hline SPF spektrofotometer $=C F \times\left(\sum_{290}^{320}(\operatorname{EE}(\lambda) \times I(\lambda))\right) \times A b s(\lambda)$
\end{tabular}

Perhitungan : $\quad$ SPF $=10 \times 0,5188$

$\mathrm{SPF}=\mathbf{5 , 1 8 8}$

Tabel 4. Hasil perhitungan SPF pada sampel sari buah sirsak (Annona muricata L.) konsentrasi (3\%)

\begin{tabular}{|c|c|c|c|}
\hline \multicolumn{4}{|c|}{ Sampel Sari Buah Sirsak } \\
\hline Panjang Gelombang & Absorbansi & EE $x$ I & $\operatorname{Abs} x(\operatorname{EE} x \mathbf{I})$ \\
\hline 290 & 1,494 & 0,0150 & 0,0224 \\
\hline 295 & 1,358 & 0,0817 & 0,1109 \\
\hline 300 & 1,270 & 0,2874 & 0,365 \\
\hline 305 & 1,213 & 0,3278 & 0,3976 \\
\hline 310 & 1,163 & 0,1864 & 0,2167 \\
\hline 315 & 1,107 & 0,0839 & 0,0928 \\
\hline 320 & 1,048 & 0,0180 & 0,0188 \\
\hline \multicolumn{3}{|c|}{ Total } & 1,2242 \\
\hline
\end{tabular}

Tabel 7. Hasil perhitungan SPF pada sampel sari buah sirsak (Annona muricata L.) konsentrasi (5\%)

\begin{tabular}{cccc}
\hline \multicolumn{4}{c}{ Sampel Sari Buah Sirsak } \\
\hline Panjang Gelombang & Absorbansi & EE $\boldsymbol{x} \mathbf{I}$ & Abs $\boldsymbol{x}(\mathbf{E E} \boldsymbol{x}$ I) \\
290 & 2,117 & 0,0150 & 0,0317 \\
295 & 1,911 & 0,0817 & 0,1561 \\
300 & 1,787 & 0,2874 & 0,5135 \\
305 & 1,710 & 0,3278 & 0,5605 \\
310 & 1,639 & 0,1864 & 0,3055 \\
315 & 1,560 & 0,0839 & 0,1308 \\
320 & 1,483 & 0,0180 & 0,0266 \\
& Total & & 1,7247 \\
\hline
\end{tabular}

Perhitungan : $\quad$ SPF $=10 \times 1,7247$

$\mathrm{SPF}=\mathbf{1 7 , 2 4 7}$ 


\section{B. Pembahasan}

Pemaparan sinar matahari yang berlebihan pada kulit mengakibatkan terjadinya reaksi fisiologis kulit, seperti keriput, pigmentasi, eritema, tannin (pencoklatan kulit) bahkan kanker kulit. Secara alamiah kulit manusia sudah memiliki sistem perlindungan terhadap radiasi matahari. Melanogenesis merupakan proses pembentukan melanin dari tirosin. Melanin memiliki kemampuan untuk melindungi kulit dari pengaruh buruk sinar UV. Pembentukan melanin merupakan suatu proses yang terbatas dan pada batas tertentu kulit tidak mampu lagi memproduksi melanin, sehingga diperlukan perlindungan tambahan yang dapat mencegah efek dari sinar UV. Untuk mencegah semua bahaya yang ditimbulkan oleh sinar matahari, sangatlah penting menggunakan tabir surya. Hasil penelitian yang telah dilakukan menyatakan bahwa penggunaan tabir surya setiap hari ternyata dapat menurunkan probabilitas terjadinya kanker kulit serta gangguan kulit lainnya (Sutarna, 2016).

Untuk mengetahui efektivitas sediaan sunscreen atau kemampuan menahan cahaya ultraviolet, tabir surya dinilai dalam faktor proteksi cahaya dinyatakan dengan nilai SPF (Sun protection factor). Sun protection factor (SPF) merupakan indikator universal yang menjelaskan tentang keefektifan dari suatu produk atau zat yang bersifat UV protektor, semakin tinggi n ilai SPF dari suatu produk atau zat aktif tabir surya maka semakin efektif untuk melindungi kulit dari pengaruh buruk sinar UV (Putra et al, 2012).

Tabir surya mempunyai fungsi dapat menyerap, memantulkan atau menghamburkan energi sinar surya yang mengenai kulit manusia, sehingga dapat melindungi kulit dari terjadinya eritema karena paparan sinar matahari. Tanpa tabir surya kulit yang terpapar sinar matahari langsung akan bertahan selama 10 menit sebelum kulit menjadi terbakar dan merah, maka pemilihan tabir surya didasarkan atas nilai SPF dikalikan dengan 10 menit yang menunjukkan daya tahan tabir surya dalam melindungi kulit. Misalnya seseorang memakai tabir surya dengan SPF 15 maka tabir surya tersebut dapat melindungi kulit selama $15 \times 10$ menit $=150$ menit atau 2 jam 30 menit dari paparan sinar ultraviolet sebelum kulit menjadi terbakar dan merah (Widiansyah, 2002).

Penggunaan antioksidan pada sediaan tabir surya dapat meningkatkan aktivitas fotoprotektif. Penggunaan zat-zat yang bersifat antioksidan dapat mencegah berbagai penyakit yang ditimbulkan oleh radiasi sinar UV (Putra et al, 2012).

Pada penelitian ini menggunakan buah sirsak (Annona muricata L.) sebagai bahan untuk perlindungan sinar UV. Dimana buah sirsak (Annona muricata L.) yang digunakan disini yaitu buah sirsak yang telah matang. Alasan digunakan buah sirsak (Annona muricata L.) karena buah sirsak mengandung vitamin $\mathrm{C}$, dimana senyawa tersebut berguna sebagai antioksidan alami didalam tubuh, yaitu membantu tubuh untuk melawan berbagai macam radikal bebas yang masuk ke dalam tubuh dan memperlambat proses penuaan (Burhan, 2012). Buah ini juga memiliki kandungan senyawa polifenol yang tinggi, karbohidrat terutama fruktosa dan kandungan vitamin C, vitamin B1 dan B2 (Prasetyorini et al. 2014).

Metode yang digunakan pada penelitian ini yaitu metode Spektrofotometri UV-Vis karena Spektrofotometri UV-Vis dapat menentukan sampel yang berupa larutan, yang akan diujikan secara in vitro dengan alat spektrofotometri UV- Vis untuk mengukur perbedaan absorbsi antara sampel oleh sinar UV pada panjang gelombang 290-320 nm. Hasil absorbansinya dicatat kemudian dihitung nilai SPFnya. Penentuan nilai SPF ini menggunakan persamaan Mansur.

Penelitian aktivitas perlindungan sinar UV sari buah sirsak (Annona muricata L.) dengan menggunakan metode spektrofotometri UV-Vis hasil yang didapatkan bahwa nilai SPF sampel sari buah sirsak (Annona muricata L.) pada konsentrasi 1\% sudah dapat memberikan aktivitas sebagai perlindungan sinar UV yang dihitung menggunakan persamaan Mansur yang dapat dilihat pada Tabel 3.

Berdasarkan hasil pengukuran nilai SPF dengan menggunakan persamaan Mansur, maka diperoleh nilai SPF dari sari buah sirsak (Annona muricata L.) dengan konsentrasi $1 \%$ adalah 5,188 (perlindungan sedang), artinya nilai SPF 5 x 10 menit $=50$ menit bertahan dibawah sinar matahari langsung, konsentrasi 3\% adalah 12,242 (perlindungan maksimal), artinya nilai SPF $12 \times 10$ menit $=120$ menit bertahan di bawah sinar matahari langsung dan konsentrasi 5\% adalah 17,247 (perlindungan ultra), artinya nilai SPF 17 x 10 menit $=170$ menit bertahan di bawah sinar matahari langsung. Semakin tinggi konsentrasi yang digunakan maka nilai SPF yang diperoleh semakin baik. Adapun pembagian dari kelas SPF tersebut diklasifikasikan sebagai berikut, SPF $2-4$ perlindungan minimal, SPF $4-6$ perlindungan sedang, SPF $6-8$ perlindungan ekstra, SPF $8-15$ perlindungan maksimal dan SPF $\geq 15$ perlindungan ultra (Nauclea 2015).

\section{KESIMPULAN}

Dari hasil penelitian yang telah dilakukan dapat disimpulkan bahwa berdasarkan nilai Sun Protection Factor (SPF), sari buah sirsak (Annona muricata L.) memiliki nilai aktivitas perlindungan 
sinar UV sedang yaitu 5,188 pada konsentrasi $1 \%$, perlindungan maksimal yaitu 12,242 pada konsentrasi 3\% dan perlindungan ultra yaitu 17,247 pada konsentrasi $5 \%$.

\section{DAFTAR PUSTAKA}

Malsawmtluangi, C, Nath, DK, Jamatia, I, Zarzoliana, E \& Pachuau, L 2013, 'Short Communication: Determination of Sun Protection Factor (SPF) number of some aqueous herbal extracts', Journal of applied pharmaceutical science, 3(9), pp. 150-151.

Mbanga, L, Mulenga, M, Mpiana, PT, Bokolo, K, Mubwa, M \& Mvingu, K 2014, 'Determination of Sun Protection Factor (SPF) of Some Body Creams and Lotions Marketed in Kinshasa by Ultraviolet Spectrophotometry', International Journal of Advanced Research in Chemical Science (IJARCS), 1(8), pp. 7-13.

Nauclea, B 2015, 'Uji Potensi Sebagai Tabir Surya Secara in Vitro Fraksi Etil Asetat Kulit Batang Tanaman Bangkal (Nauclea subdita)', pp. 6-7.

Pradika, Y 2016, Uji Aktivitas Tabir Surya Ekstrak Batang Pisang Ambon (Musa paradisiaca var. sapientum), Doctoral dissertation, Fakultas Sains dan Teknologi, Universitas Islam Negeri Sunan Kalijaga.Prasetyorini et al. 2014

Prasetyorini, P, Moerfiah, M, Wardatun, S \& Rusli, Z 2014, 'Potensi antioksidan berbagai sediaan buah sirsak (Annona muricata Linn)', Penelitian Gizi dan Makanan The Journal of Nutrition and Food Research, 37(2 Dec), pp. 137-144.

Putra, DP \& Susanti, M 2012, 'Aktivitas perlindungan sinar UV kulit buah Garcinia mangostana Linn secara in vitro', pp. 61-64.

Sutarna, TH, Alatas, F, Ratih, H, Anggraeni, W \& Purnamasari, N 2016, 'Pengaruh penambahan vitamin $\mathrm{C}$ sebagai antioksidan terhadap nilai Sun Proctective Factor (SPF) dari Oktil Metoksisinamat'.

Widiansyah, A 2002, 'Uji Banding Waktu Pemakaian Ulang Tabir Surya SPF 15 dan SPF 30 yang Paling Efektif Pada Pemain Tenis di Luar Ruangan', Doctoral dissertation, Program Pendidikan Pasca sarjana Universitas Diponegoro. 